\title{
STUDY AND IMPLEMENTATION OF THE PASSIVE-BASED CONTROL LAW FOR THE BOOST INVERTER
}

\author{
Nimrod Vázquez, Claudia Hernández, Elías Rodríguez, Jaime Álvarez*, Jaime Arau** \\ Instituto Tecnológico de Celaya \\ Electronics department \\ Celaya, Gto, Mexico \\ n.vazquez@ieee.org \\ *CINVESTAV \\ Electric department, Mecatronics Section \\ Mexico, D.F, México \\ j.alvarez@mail.cinvestav.mx \\ **enidet \\ Electronics department \\ Cuernavaca, Mor, México \\ j.arau@ieee.org
}

\begin{abstract}
The passivity-based control has been proposed to control different non-linear systems, but practical implementation aspects have not been discussed on most of them. One of those systems is the buck inverter. In some applications it is necessary the boosting capability additionally to the inversion capability, therefore a boost inverter has been proposed in those cases, since the buck inverter does not have those capabilities. In this paper the practical implementation of the passivity-based control for the boost inverter is discussed in some detail, and a modified controller is proposed to overcome the implementation drawbacks.
\end{abstract}

Keywords - Boost inverter, Implementation, Passivity

\section{Nomenclature}

C - Capacitor of the current emulator

d - Duty cycle

$e_{z_{1}}$ - Output of the current emulator

$\mathrm{G}_{\mathrm{m}}$ - Maximum gain

$\mathrm{I}_{\mathrm{L}} \quad$ - Inductor current

$\mathrm{I}_{\mathrm{o}} \quad$ - Output current

$\mathrm{k}_{\mathrm{p}}, \mathrm{k}_{\mathrm{i}}$ - PI controller parameters

$\mathrm{R}_{\mathrm{n}} \quad$ - Controller parameters

$\mathrm{R}$ - Resistance of the current emulator

$\mathrm{u}_{\mathrm{n}}$ - Control law

$\mathrm{V}_{\mathrm{a}}$ - Capacitor voltage

$\mathrm{V}_{\text {in }}$ - Input voltage

$\mathrm{V}_{\mathrm{dc}}$ - Dc Component of the capacitor voltage

$\mathrm{V}_{\text {op }}$ - Peak output voltage

$\mathrm{Z}_{1}, \mathrm{Z}_{3}$ - Inductor current

$\mathrm{Z}_{2}, \mathrm{Z}_{4}$ - Capacitor voltage

$\widetilde{Z}$ - State error vector

$\widetilde{z}_{2}$ - Capacitor voltage error

$\mathrm{Z}_{\text {nd }} \quad$ - Reference of the state variable

\section{INTRODUCTION}

The dc/ac conversion is widely used in many applications; two of these applications are the uninterruptible power supplies and the photovoltaic systems. In these two systems it is usually necessary the boosting capability, additionally to the inversion capability. One converter proposed for those applications is the boost inverter, since the traditional buck

Manuscript received February 5th, 2005. First review April 14, 2005. Second review May 25, 2005. Recommended by Special Editors Marcelo G. Simões and Humberto Pinheiro. inverter does not have those referred capabilities. The boost inverter can to boost and to invert at the same time [1-2].

The boost inverter is a complex system from the control point of view. This is because the converter must generate a sinusoidal output plus a dc component in each branch of the converter (tracking problem), and also the system is non minimum phase with respect to the variable to be controlled. It is a difficult task to control the converter.

In [3-7] a sliding mode control and a double loop controller for the boost inverter have been proposed. In this paper a passivity based control scheme is studied to solve the tracking problem for the boost inverter. The system is non minimum phase if the voltage load is taken as the system output, then it could be controlled indirectly through the inductor current. The document also present how to tackle some practical implementation problem, this is made modifying the controller.

The operation of the boost inverter, the analysis of the control strategy, and the design considerations that should be taken into account to implement the modified passivity-based control are discussed.

In next section a boost inverter model is presented; in section three the passivity-based control is addressed, with the design considerations to implement the controller; in section four the simulation and experimental results are presented; and finally some conclusions will be given.

\section{THE BOOST INVERTER}

The boost inverter features an excellent property: it naturally generates an output ac voltage lower or larger than the dc input voltage, depending on its duty cycle [1-2]. This property is not found in the traditional full bridge inverter, which produces an instantaneous ac output voltage always lower than the input dc voltage as was mentioned before.

The boost inverter achieves dc/ac conversion as follows: the power stage consists of two current bi-directional boost converters and the load is connected differentially across them (Fig. 1). These converters produce a dc-biased sinusoidal waveform (Fig. 2). The modulation of each converter is 180 degrees out of phase with respect to the other, which maximizes the voltage excursion over the load [1-2].

Considering the behavior before mentioned, the analysis of the converter in steady state is made. According to Fig 2, the branch voltage $\mathrm{Va}[4]$ :

$$
V_{a}=V_{d c}+\frac{V_{o p}}{2} \operatorname{Sin}(w t)
$$


Where:

$$
\begin{array}{ll}
V_{d c} & \text {-DC Component }\left(V_{i n}+\frac{V_{o p}}{2}\right) \\
w & \text {-Output frequency }(2 \pi f) \\
V_{o p} & \text { - Peak output voltage }
\end{array}
$$

The gain of the branch versus the duty cycle (d) is [4]:

$$
V_{a}=\frac{V_{\text {in }}}{1-d}
$$

Using (1), (2) and knowing that $V_{o}=2 V_{a}-2 V_{d c}$, the gain of the converter is obtained as:

$$
\frac{V_{o}}{V_{i n}}=\frac{2 d-\mathrm{G}_{\mathrm{m}}(1-d)}{1-d}
$$

Where:

$\mathrm{G}_{\mathrm{m}}$-Maximum gain $\left(\mathrm{V}_{\mathrm{op}} / \mathrm{V}_{\mathrm{in}}\right)$,

d -Duty cycle

The inductor current as a function of the duty cycle is [4]:

$$
I_{L}=I_{o} \frac{1}{1-d}
$$

Where:

$\mathrm{I}_{\mathrm{o}} \quad$ - Output current

With (2) and (4) is obtained that:

$$
I_{L}=I_{o} \frac{V_{a}}{V_{i n}}
$$

It is important to notice that the inductor current has a non-conventional form (Fig. 3), and also depends on the load $\left(\mathrm{I}_{0}\right)$. The variable to control is the capacitor voltage following a sinusoidal trajectory.

\section{A. System modeling}

For control purposes it is necessary to obtain the model of the system to be controlled. Fig. 4 shows the simplified circuit used for the boost inverter. For modeling purposes it is assumed that all the components are ideal and the circuit operates in continuous conduction mode.

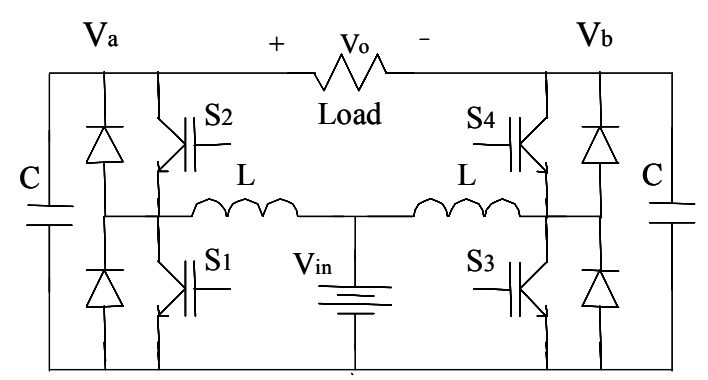

Fig. 1. Boost inverter.
This model permits to emulate every load and verify the performance at any load, because the load is modeled as a current source. In a previous paper it just has been modeled the converter for each branch and the load as a resistance, that model in consequence is incomplete because the load is not necessarily a resistance [3-7].

The two control variables $u_{1}$ and $u_{2}$ only affects two different state variables; $u_{1}$ affects $z_{1}$ and $z_{2}$, and $u_{2}$ affects $z_{3}$ and $\mathrm{z}_{4}$, then the system is uncoupled. This is possible because the load is represented by a current source. The following system can be used just for controller design:

$$
\left[\begin{array}{cc}
L & 0 \\
0 & C
\end{array}\right]\left[\begin{array}{l}
z_{1} \\
\dot{z}_{2}
\end{array}\right]+\left[\begin{array}{cc}
0 & 1 \\
-1 & 0
\end{array}\right]\left[\begin{array}{c}
z_{1} \\
z_{2}
\end{array}\right]\left(1-u_{1}\right)=\left[\begin{array}{c}
V_{\text {in }} \\
-I_{o}
\end{array}\right]
$$

$$
\text { Or } D_{B} \dot{Z}+J_{B} Z\left(1-u_{1}\right)=E
$$

Where:

$$
\begin{array}{ll}
\mathrm{z}_{1} & \text { - Inductor current } \\
\mathrm{z}_{2} & \text { - Capacitor voltage } \\
\mathrm{u}_{1} & \text { - Control law } \\
\mathrm{V}_{\mathrm{in}} & \text { - Input voltage }
\end{array}
$$

From (6) it can be observed that if either $z_{1}$ or $z_{2}$ is the output, then the relative degree of the system is one. Model (6) is a bilinear non-minimum phase system if $z_{2}$ is taken as the output. It is well known that exact tracking can not be achieved by a non-minimum phase system because any control law would render the closed loop system unstable.

As it was mentioned before the inductor current depends on the load, then to control the converter with passivity based controller is relatively complex; also as the output voltage is not controlled directly, the parasitic resistance or losses must be considered at the control law. This paper presents a method to implement the passivity-based controller considering these facts.
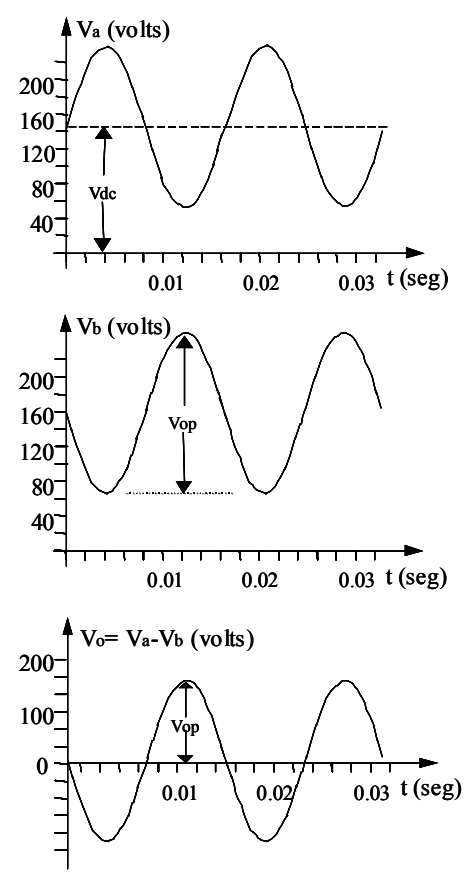

Fig. 2. Output voltage for each dc-dc converter. 


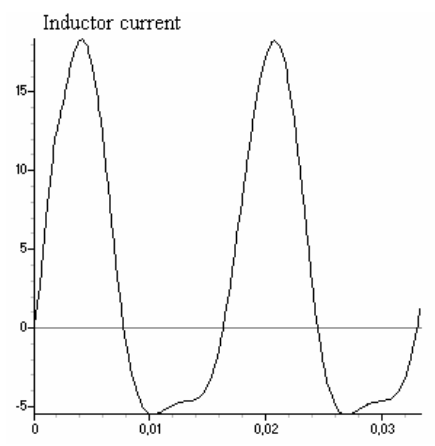

Fig. 3. Inductor current form: resistive load.

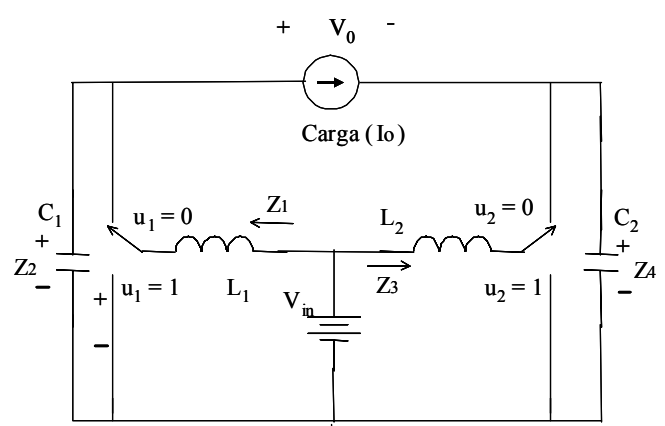

Fig. 4. Simplified circuit of the boost inverter.

\section{THE PASSIVITY BASED CONTROL}

The passivity theory is related to the energy dissipation of physic systems. A passive system is relatively easy to control in the sense that the system is naturally stable [8]. This property makes the passivity-based controller an interesting option, but it has some inconveniences when it is implemented.

At difference with the Sliding Mode Control (SMC) the passivity based controller naturally assures stability, due to the properties of the passive systems [8]. The SMC is based on a sliding surface, the system is obligated to remain into the sliding surface; and then the stability analysis must be done to assure that the system will reach the equilibrium point. The passive based controller starts with a stable system to find the control law.

The system to be controlled, equation (6), is naturally not passive, but through the control law the system becomes passive. The motivation is to assure the stability obligating to the system to has the behavior of a stable passive system, then the control law is chosen with the purpose to obtain a stable passive system behavior.

It is important to remark that both controllers offer to the system a good dynamic response.

Despite of the good characteristics of the passivity based controller, it has some inconveniences when it is implemented, which it is discussed in this paper.

\section{A. Obtaining the passive-based control law}

Summarizing, the passivity control law can be obtained by the next steps: i) Obtain the system model, ii) Propose an error system with the desired dynamic, this system must be passive, iii) Found the control law that makes the system follows the error system proposed.

The first step has been made in the previous section, for the second step the passive error system proposed is [8]:

$$
D_{B} \dot{\widetilde{Z}}+\left(1-u_{1}\right) J_{B} \widetilde{\mathrm{Z}}+R_{B d} \widetilde{\mathrm{Z}}=0
$$

Where:

$$
\begin{array}{ll}
R_{B d}= & \left.\begin{array}{cc}
R_{1} & 0 \\
0 & R_{2}
\end{array}\right], R_{1}>0, \quad R_{2}>0, \\
\widetilde{Z} & \text { - Error vector of the state variables } \\
\widetilde{z}_{2} & \text { - Capacitor voltage error }\left(z_{2}-z_{2 d}\right) \\
\mathrm{R}_{\mathrm{n}} & \text { - Controller parameters }
\end{array}
$$

The conditions $R_{1}>0$ and $R_{2}>0$, must be fulfilled in order to assure the stability, these terms are the dissipative elements that permit to the system becomes passive (controller parameters). A stability proof of this passive error system is made in chapter 4 , section 3.3 of the reference [8].

In the third step the control law is obtained. The reference system is obtained using (6) and (7) resulting:

$$
\begin{aligned}
L \dot{z}_{1 d}+\left(1-u_{1}\right) z_{2 d}-R_{1}\left(z_{1}-z_{1 d}\right) & =V_{\text {in }} \\
C z_{2 d}-\left(1-u_{1}\right) z_{1 d}-R_{2}\left(z_{2}-z_{2 d}\right) & =-I_{o}
\end{aligned}
$$

Where:

$$
\begin{array}{ll}
\mathrm{z}_{1 \mathrm{~d}} & \text { - Inductor current reference } \\
\mathrm{z}_{2 \mathrm{~d}} & \text { - Capacitor voltage reference } \\
\mathrm{u}_{1} & \text { - Control law }
\end{array}
$$

From (8) the following control law is obtained:

$$
u_{1}=1-\frac{V_{\text {in }}+R_{1}\left(z_{1}-z_{1 d}\right)-L z_{1 d}}{z_{2 d}}
$$

It is important to note that there are not singularities in the control law despite that $z_{2 d}$ is at the denominator of (9). $z_{2 d}$ is the capacitor voltage reference, and this voltage must be like the desired capacitor voltage $\left(\mathrm{V}_{\mathrm{a}}\right)$ shown in Fig. 2; this voltage is always higher than zero volts and higher than the input voltage, this is because the $\mathrm{dc} / \mathrm{dc}$ boost converter can not produce a voltage lower than the input voltage.

The control law should include the input voltage to eliminate perturbations at the output voltage due to this variable. As the inductance is too small this term was neglected. The controller parameter is used to adjust the system performance. The control law depends on the inductor current reference, and as it was mentioned before, that reference changes with the load.

To avoid the generation of the reference current an emulator is used. To emulate the current error the solution of the following differential equation is used (Fig 5):

$$
\frac{d}{d t} e_{Z_{1}}=z_{1}-\frac{e_{Z_{1}}}{R C}
$$


Where:

$\mathrm{e}_{1}$ - Output of the current emulator

$\mathrm{R}, \mathrm{C}$ - Parameters of the current emulator

As the controller does not operate directly with the output voltage, an error related with the parasitic elements may occur, even worst as a tracking is performed. To eliminate that problem another loop is added to the term $V_{\text {in }}$ of the control law:

$$
A=k_{p} * \widetilde{z}_{2}+k_{i} * \int \widetilde{z}_{2} d t
$$

Where:

$\widetilde{z}_{2} \quad$-Error of the capacitor voltage $\left(z_{2}-z_{2 d}\right)$

The implemented control law is then:

$$
u_{1}=1-\frac{V_{i n}+k_{p} * \widetilde{z}_{2}+k_{i} * \int \widetilde{z}_{2} d t+R_{1} e_{Z_{1}}}{z_{2 d}}
$$

The output of the error current emulator is obtained from (10), this is made with the circuit of the Fig 6.

To sintonize the controller parameters has four steps: first cancellate the $\mathrm{k}_{\mathrm{p}}$ and $\mathrm{k}_{\mathrm{i}}$ parameters, and increase $\mathrm{R}_{1}$ until the output becomes the desired sinusoidal output; this is made at no load. As second step, connecting the load, increase the $\mathrm{k}_{\mathrm{p}}$ until the steady state error is almost eliminated. As third step increase the $\mathrm{k}_{\mathrm{i}}$ parameter to have a better response; it is important to note that in this controller the steady state error is eliminated with $\mathrm{k}_{\mathrm{p}}$. And finally $\mathrm{RC}$ is a constant time chosed according to the switching frequency $\left(f_{s}\right)$, that is $R C=1 /\left(0.2 \pi f_{s}\right)$.

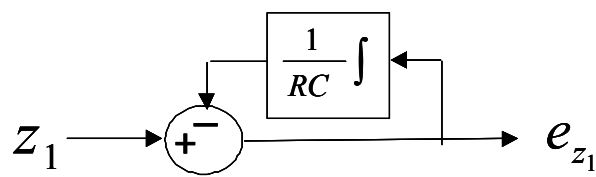

Fig. 5. Error emulator.

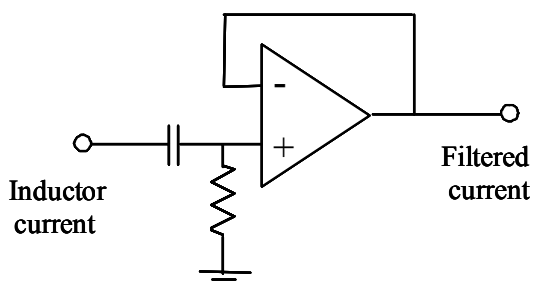

Fig. 6. Inductor error current emulator.

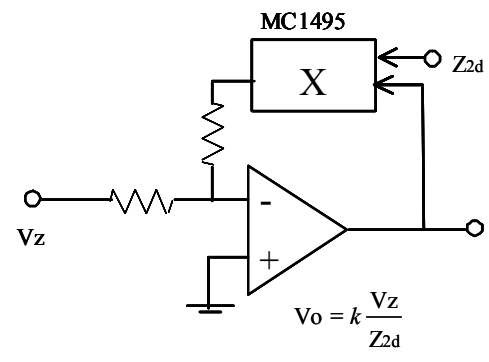

Fig. 7. Basic divisor circuit.

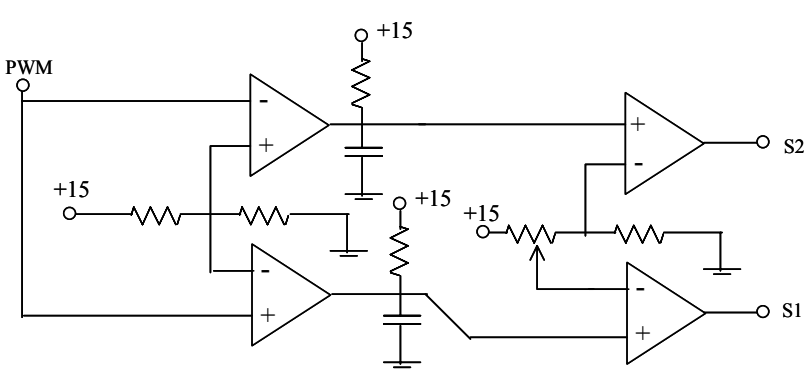

Fig. 8. Dead time circuit.

\section{B. Experimental circuits}

The controller was built experimentally; some important practical circuits to implement it are the high pass filter (current emulator), the divisor, the PWM generator and the dead time generator.

The error current emulator is made with a high pass filter (Fig. 6), this simple circuit permits eliminate the generation of the inductor current reference. For the divisor circuit a multiplier in configuration as divider is used (Fig 7), the multiplier used for this purpose is the MC1495 integrated circuit. For the pulse with modulator (PWM) generation the TL494 integrated circuit is used. The control law discussed in the previous section is introduced in this circuit to obtain the pulses that determine the turn off and turn on of the boost inverter semiconductors.

Inverter topologies always need a dead time generator for the semiconductors of the inverter branches, in order to avoid a short circuit on the branch. The circuit used for this purpose is shown in Fig 8; just one integrated circuit is used for this purpose (LM339).

To turn on and turn off properly the semiconductors a gate driver must be used for each one. The gate driver used is the M57959L of POWEREX. This circuit includes protection of malfunction and over stress.

\section{SIMULATION AND EXPERIMENTAL RESULTS}

Some simulation and experimental results of the converter are shown in Figs. 9-12. The converter parameters are $\mathrm{V}_{\text {in }}=$ $50 \mathrm{~V}, \mathrm{~V}_{\mathrm{o}}=120 \mathrm{~V}_{\mathrm{ac}}\left(\mathrm{G}_{\mathrm{m}} \approx 3.4\right), \mathrm{L}=360 \mu \mathrm{H}, \quad \mathrm{C}=27 \mu \mathrm{F}$ and $\mathrm{P}_{\mathrm{o}}=300 \mathrm{VA}$.

The simulation results of the converter are shown in Fig. 9, the output voltage and current are shown under a load variation, also the capacitor voltage, the input voltage and the control law. 
The experimental results are shown in Figs. 10-13. These experimental results of Figs. 10 and 11 were made with a resistive load at $150 \mathrm{~W}$. In Fig. 10 it is shown the capacitor voltage, and the input voltage without compensation of the parasitic elements. As it can be observed the voltage is distorted, and so the output voltage is also distorted. In Fig. 11 it is shown the output voltage with the compensation of the parasitic elements, as it can be observed the voltage is not distorted. The compensation is made including (11) to the control law, that is (12) is used.

In fig 12 is shown the performance of the prototype under load variations, as it can be observed the system has a good performance. The load changes from $20 \%$ to $80 \%$ of the total power, the total power is $300 \mathrm{~W}$.
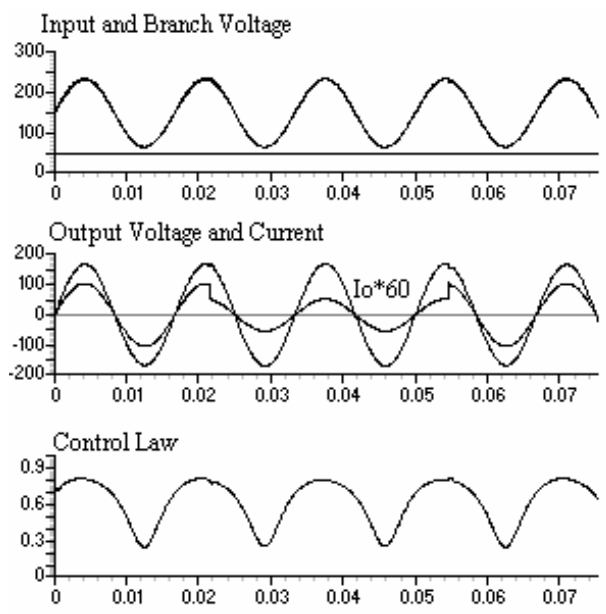

Fig. 9 Simulation results under load variation.

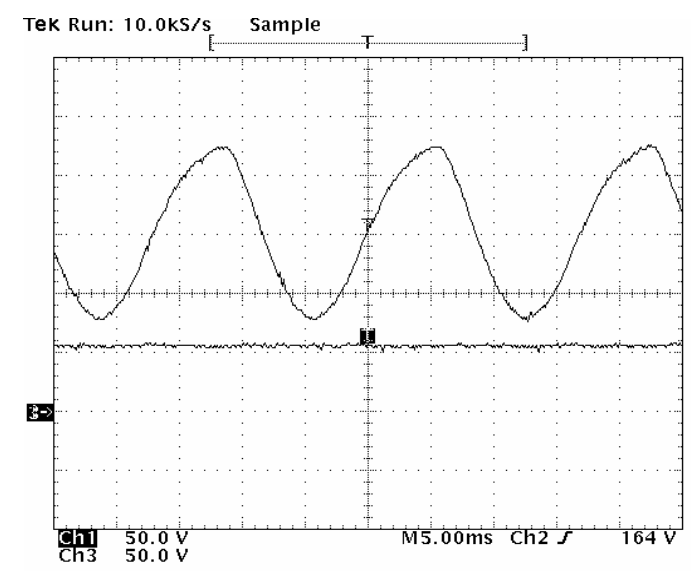

Fig. 10 Top to down: Capacitor voltage, input voltage. System without compensation of the parasitic elements.

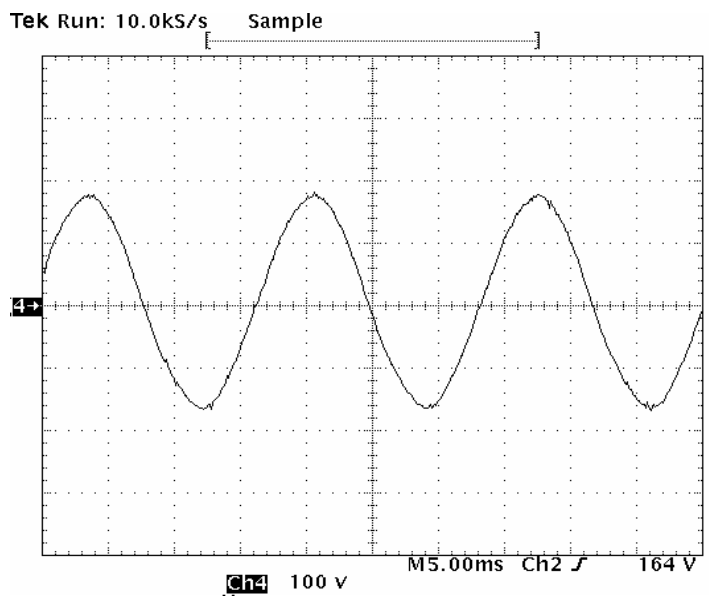

Fig. 11 Output voltage. System with compensation of the parasitic elements.

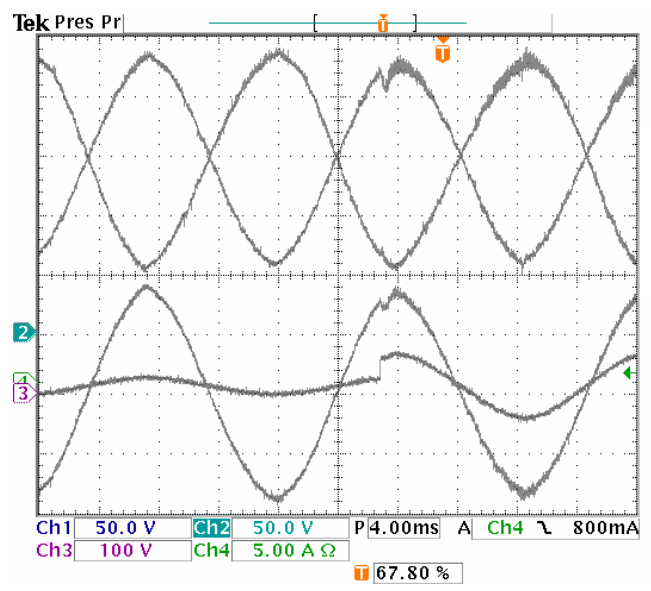

Fig. 12 Inverter under load variation: Top to down: Branch voltages, Output voltage and output current, with compensation of the parasitic elements.

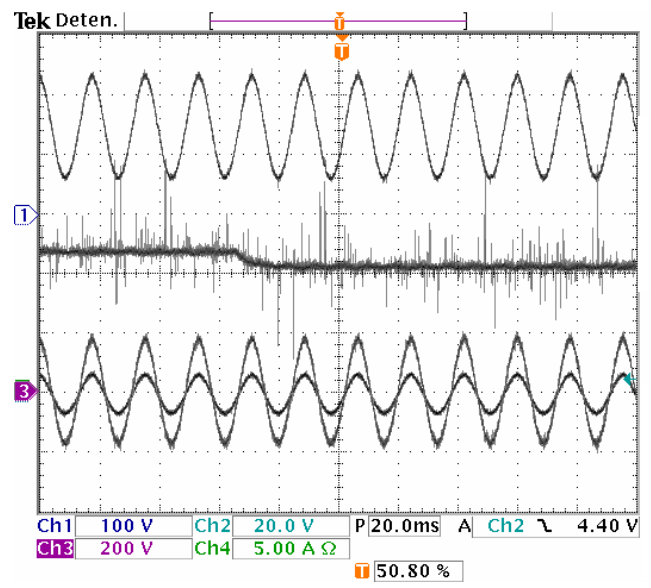

Fig. 13 Inverter under input voltage variation: Top to down: Branch voltage, Input voltage, Output voltage and output current. 


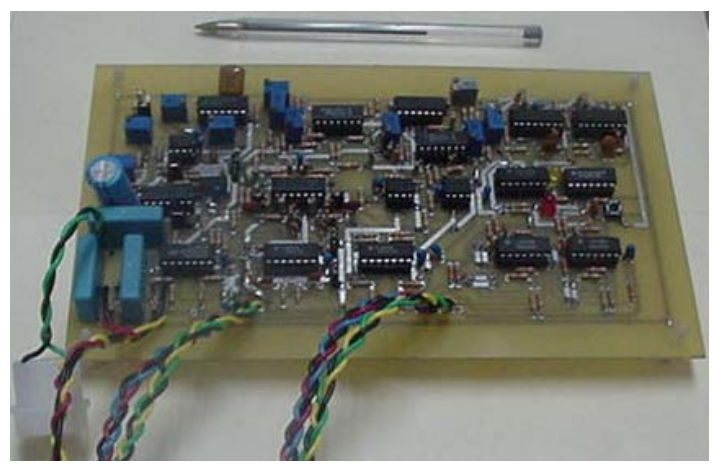

Fig. 14 Photo of the passivity based controller.

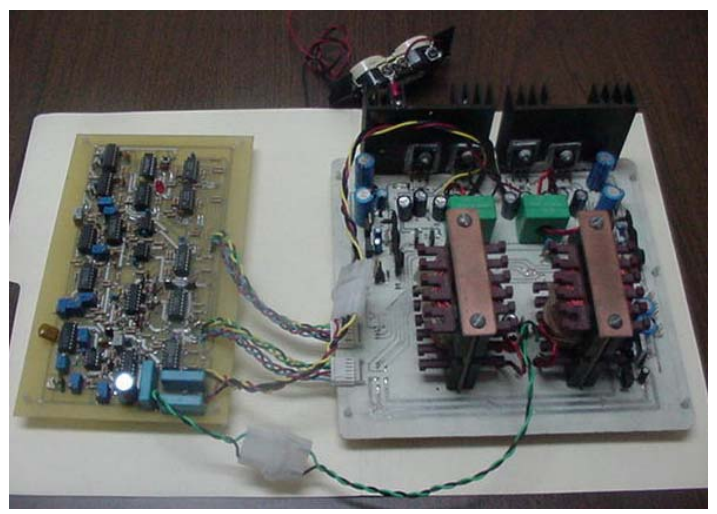

Fig. 15 Photo of the complete system.

In Fig 13 it is shown the performance of the system under an input voltage variation at full load. The input voltage changes from $50 \mathrm{~V}$ to $45 \mathrm{~V}$. A good response is observed, no distortion is observed at the output voltage.

In Fig 14 and 15 is shown a photo of the implemented prototype. One of them is the controller and the other one is the complete system.

The THD at full load for the output voltage is $3.5 \%$

\section{CONCLUSIONS}

In this paper a boost inverter is analyzed using a passivity based controller. The boost inverter is used in uninterruptible power supplies and photovoltaic systems when it is necessary to boost the input voltage additionally to the inversion capability. The converter is a non-minimum phase system with respect to the variable to be controlled. Then the tracking problem makes the task much more difficult.

In this paper the passivity based control with the tracking problem at the boost inverter is analyzed, and a modified controller is proposed. The analysis, operation, simulation and experimental results are presented.

\section{ACKNOWLEDGEMENT}

The authors wish to acknowledge to CoSNET that sponsored this project.

\section{REFERENCES}

[1] R. Cáceres, I. Barbi. "A boost dc-ac converter: operation, analysis, control and experimentation", Proceedings of the international conference on industrial electronics, control and instrumentation IECON 95, pp 546-551.

[2] N. Vázquez, C. Aguilar, J. Arau, R. Cáceres, I. Barbi, J. Alvarez. "A Novel Uninterruptible Power Supply System with Active Power Factor Correction", IEEE Transactions on Power Electronics. Vol 17. pp 405412. Mayo 2002.

[3] I. E. Colling, I. Barbi, “ A reversible step-up voltage source inverter controlled by sliding mode". IEEE Power Electronics Specialists Conference-PESC'99, pp. 538 543.

[4] N. Vazquez, J. Alvarez, C. Aguilar, J.Arau. "Some critical aspects in sliding mode control for the boost inverter" IEEE International Power Electronics Conference CIEP'98, pp 76-81.

[5] R. Caceces, I. Barbi "Sliding mode controller for the boost inverter" IEEE International Power Electronics Conference CIEP'96, pp 247-252.

[6] R. Fuentes, H. Pinheiro. "Non-isolated singele phase UPS based on step-up converters". IEEE International Power Electronics Congress -CIEP'00, pp. 353 - 358

[7] P. Gurpide, O. Alonso, L. Marroyo, T. Meynard, E. Lefeuvre. "A new control strategy for the boost inverter" IEEE Power Electronics Specialists Conference PESC 2001, pp 974-979.

[8] R. Ortega, A. Loria, P. Nicklasson, H. Sira. Passivitybased control of Euler-Lagrange Systems. Ed. Springer, 1998.

\section{BIOGRAPHIES}

Nimrod Vázquez was born in México DF, México, in 1973. He received the B.S. in electronics engineering from the Instituto Tecnológico de Celaya, México in 1994, the M. Sc. degree in electronics engineering and the Dr. Ing degree from the National Center for Research and Technological Development (CENIDET), México in 1997 and 2003 respectively.

From 1994 to 1995, he was in the Research Technological Teaching Program of the Electrical Research Institute (IIE), Cuernavaca, México. In 1998, he is joined the ElectronicsEngineering Department, Instituto Tecnológico de Celaya. Dr Vázquez served as General Chair of CIEP'04 which took place in Celaya, Mexico in 2004

Claudia Hernández was born in Salamanca, Gto. México, in 1971. She received the B.S. in Electronics Engineering from the Instituto Tecnológico de Celaya, México in 1995, and the M. Sc. degree in Electronics Engineering from National Center for Research and Technological Development (CENIDET), México in 2000.

Since 1998, she is joined to the Electronics-Engineering department of the Instituto Tecnológico de Celaya.

Elias Rodriguez was born in Mexico in 1972. He received the B.Sc. degree in electronic engineering from 
Universidad Autonoma Metropolitana (UAMAzcapotzalco), D.F., Mexico, the M.Sc. in electronic engineering from the Centro Nacional de Investigacion $y$ Desarrollo Tecnologico (CENIDET), Cuernavaca, Morelos, Mexico and the Ph.D. in electronic engineering from the Centro Nacional de Investigacion y Desarrollo Tecnologico (CENIDET), Cuernavaca, Morelos, Mexico, in 1994, 1996 and 1999 respectively.

From 1999 to 2001, he was a Researcher of the Electronic Department at the Instituto Tecnologico de Celaya, Celaya, Guanajuato, Mexico, where he conducted industrial sponsored research projects, including design and control of new technologies on AC/DC converters, DC/DC converters and electronic ballast. From 2001 to 2003, he was a Senior Engineer in the Magg Iluminación, Naucalpan, Estado de Mexico, Mexico, where he designed and developed electronic ballasts for linear, circular and compact fluorescent lamps. He is currently a Professor and Researcher of the Electronic Department at the Instituto Tecnológico de Celaya, Celaya, Guanajuato, Mexico, where he teaches and conducts research in the area of power electronics.

Jaime Alvarez was born in Tampico, Mexico. In 1973 he received the B.S. degree in electronics engineering form the National Polytechnic Institute of Mexico (IPN) and the M. Sc. and $\mathrm{Ph}$. D. degrees in electrical engineering, both at the Center for Research and Advanced Studies, (CINVESTAV), in 1974 and 1978, respectively.

He has been head of the Automatic Control Section at CINVESTAV (1983-1985), head of the Department of Electrical Engineering also at CINVESTAV (1992-1996) and Director of the School of Interdisciplinary Engineering and
Advanced Technologies of the IPN (1997-2000). He also held the position of Visiting Professor at the Imperial College of Science and Technology (1985-1986) in London, England. Since 1976 he has been professor at the CINVESTAV in the Department of Electrical Engineering. Prof. Alvarez is also a National Researcher of the System of National Researchers.

Prof. Alvarez is a member of the Mexican Academy of Sciences and of the Mexican Academy of Engineering.

Jaime Arau was born in Veracruz, Mexico, in 1960. He received the B.Sc. degree in electronic engineering from the Instituto Tecnologico de Minatitlan, Mexico, and the Ph.D. degree in electrical engineering from the Universidad Politecnica de Madrid, Spain, in 1982 and 1991, respectively.

Currently, he is a Full-Time Professor and vice Director for Academic and Research affairs at the Centro Nacional de Investigacion y Desarrollo Tecnologico (CENIDET), where he reaches and conducts research in the power electronics area. His fields of interest are power-factor correction, electronics ballasts, and other topics related to power electronics in which he has published more than 100 articles in international journals and major conferences and conducted $30 \mathrm{MSc}$ and $5 \mathrm{PhD}$ theses and he has a couple of patents under review.

Inside IEEE, Dr Arau received in 2000 the 3rd Millenium Medal and he has served in different positions as the founding president of the Morelos Section Power Electronics Chapter, PELS Chapters Chair and AdCom Member, as well as the General Chair of PESC'03 which took place in Acapulco, Mexico in 2003. He is also the founding president of the Mexican Society of Power Electronics-SOMEP. 